\title{
Pedagogia social: \\ EPISTEMOLOGIA DA ESPERANÇA NO TERRITÓRIO INSTITUCIONAL
}

\author{
SOCIAL PEDAGOGY: EPISTEMOLOGY OF HOPE IN THE \\ INSTITUTIONAL TERRITORY
}

\begin{abstract}
Sergio Haddad
Doutor em Educação pela Universidade de São Paulo. Professor do Programa de Pós-graduação em Educação da Universidade de Caxias do Sul - UCS e Pesquisador da Ação Educativa ORCID: https://orcid.org/0000-0002-6243-1813 sergiohaddad@terra.com.br

Ingrid Bays

Mestre em Educação pela Universidade de Caxias do Sul - UCS. Educadora Social na Fundaçáo de Assistência Social de Caxias do Sul/RS - FAS. Advogada. ORCID: https://orcid.org/0000-0002-4249-1050 ingridbays@gmail.com
\end{abstract}

Resumo: A história da infância e da adolescência institucionalizada no Brasil permanece como objeto de estudo de pesquisadores em razão de existirem muitas questôes a serem desmistificadas, desmembradas e revisitadas. Do período da Roda dos Expostos até hoje, vigente a Constituição Federal de 1988 e o Estatuto da Criança e do Adolescente de 1990, a institucionalização ainda é um método frequente, mesmo que a legislação a trate como excepcional. O texto defende a possibilidade de trabalhar dentro desses ambientes em perspectiva educacional, apoiando-se na pedagogia social, enquanto teoria e metodologia, e no educador social, enquanto profissional que acompanha as crianças e adolescentes em situação de medida protetiva. Para tanto, apresenta resultados de investigação (em andamento) fundada em pesquisa bibliográfica sobre os temas em questão e que fundamentaram a investigação empírica realizada durante a elaboração da dissertação intitulada "A educação social e a autonomia de adolescentes em medida protetiva: uma concepção freireana no acolhimento institucional”, no Programa de PósGraduação em Educação da Universidade de Caxias do Sul, buscando contribuir para a minimização de danos nesse ambiente institucional por meio da pedagogia social, tendo-a como estratégia e como epistemologia da esperança no território institucional.

Palavras-Chave: Acolhimento Institucional; Educação Social; Epistemologia; Paulo Freire; Pedagogia Social.

Aвstract: The history of institutionalized childhood and adolescence in Brazil remains the object of study by researchers because there are many issues to be demystified, dismembered and revisited. From the period of the Wheel of the Exposed until today, in 
effect the Federal Constitution of 1988 and the Statute of the Child and the Adolescent of 1990, the institutionalization is still a frequent method, even though the legislation treats it as exceptional. The text defends the possibility of working within these environments from an educational perspective, relying on social pedagogy, as theory and methodology, and on the social educator, as a professional who accompanies children and adolescents in protective measures. To this end, it presents research results (in progress) based on bibliographic research on the themes in question, and which supported the empirical research carried out during the elaboration of the dissertation entitled "Social education and the autonomy of adolescents in protective measure: a Freirean conception. institutional reception" in the Graduate Program of the University of Caxias do Sul, seeking to contribute to the minimization of damage in this institutional environment through social pedagogy, having it as a strategy and as an epistemology of hope in the institutional territory.

KeYwords: Institutional Hosting; Social Education; Epistemology; Paulo Freire; Social Pedagogy.

\section{Introduçáo}

A partir da adoção da doutrina da proteção integral, prevista na Constituição Federal (CF) de 1988 e, posteriormente, no Estatuto da Criança e do Adolescente (ECA) de 1990, todas as crianças e adolescentes passariam a ser considerados sujeitos de direitos e foco de prioridade absoluta da família, do Estado e da sociedade, justamente por estarem em desenvolvimento e necessitarem de proteção especial e garantia de seus direitos por parte dos adultos. Teoricamente, com a promulgaçáo da legislação extravagante, muitas práticas adotadas em outras épocas deveriam ser abandonadas, notadamente aquelas inerentes às instituiçóes de acolhimento de crianças e adolescentes.

Institui-se, oficialmente, a socioeducação. As instituições que antes abriam as portas, tanto para crianças e adolescentes que cometiam ato infracional quanto para aqueles que estavam em situação de vulnerabilidade social - situação de rua ou até mesmo de abandono, violência ou negligência por parte dos familiares -, passariam a ter normativas que proíbem tal junção. Com o advento do ECA, passariam a existir as medidas socioeducativas e as medidas protetivas. $\mathrm{Na}$ presente pesquisa, focamos uma modalidade de acolhimento institucional denominada 'abrigo', na qual estão inseridas crianças e adolescentes em situação de medida protetiva, de acordo com o artigo 98 do Estatuto. As medidas específicas de proteção 
não são punitivas e, como o próprio nome legitima, têm cunho educativo, propondo-se a fazer cumprir os direitos da criança e do adolescente por aqueles que os estão violando, sejam eles pais ou responsáveis, sociedade ou Estado, objetivando a preservação ou a recomposição dos direitos fundamentais de crianças e adolescentes. (MACHADO, 2003, p. 206)

As estratégias, delimitadas pelos documentos legais, que perpassam a Declaração Universal dos Direitos da Criança (1959), a Constituição Federal (1988), o Estatuto da Criança e do Adolescente (1990), a Convenção Sobre os Direitos da Criança (1990), a Lei Orgânica de Assistência Social (1993), a Política Nacional de Assistência (2004), o Plano Nacional de Convivência Familiar e Comunitária (2006); as diretrizes internacionais: Crianças Privadas de Cuidados Parentais (2006); as orientaçóes técnicas: Serviços de Acolhimento para Crianças e Adolescentes (2009), Tipificação Nacional de Serviços Socioassistenciais (2009) e a Lei no 12.010/2009, caminham juntas no sentido de, entre outras coisas, buscarem a desinstitucionalização, preservando-se os vínculos familiares e comunitários.

No entanto, segundo Levantamento Nacional das Crianças e Adolescentes em Serviços de Acolhimento (ASSIS; FARIAS, 2013), realizado entre os anos de 2009 e 2010, existiam naquele período 2.624 (dois mil seiscentos e vinte e quatro) serviços de acolhimento institucional no país (levando-se em consideração os serviços na modalidade institucional e familiar, ou seja, abrigo institucional, casa-lar e serviço de acolhimento em família acolhedora), atendendo um total de 36.929 (trinta e seis mil novecentas e vinte e nove) crianças e adolescentes. Desse total, 64,2\% estavam na modalidade 'abrigo institucional'. É preciso encarar, portanto, o fato que a intenção legal se distancia da prática. Pensando nisso, faz-se necessário o enfrentamento dessa realidade, refletindo-se sobre os próprios locais de acolhimento e sobre essas crianças e adolescentes institucionalizados, valendo-se da figura do educador prevista nas Orientaçóes Técnicas: Serviços de Acolhimento para Crianças e Adolescentes (2009).

O objetivo deste artigo é o de refletir sobre a questão da institucionalização, por meio de um exame fundado em pesquisa bibliográfica que fundamentou dissertação "A educação social e a autonomia de adolescentes em medida protetiva: uma concepção freireana no acolhimento institucional", no Programa de Pós-Graduação em Educação da Universidade de 
Caxias do Sul, buscando, dessa forma, contribuir para a minimização de danos nesse ambiente institucional por meio da pedagogia social.

\section{O Acolhimento Institucional e o Educador Social no Abrigo}

A institucionalização de crianças e adolescentes é um tema há muito pesquisado, notadamente pelos estudiosos da área social. Nosso país possui um longo histórico de institucionalização, que perpassa o desenvolvimento do propósito assistencial brasileiro em fases que são definidas por Silva (1997, p. 34-36) como filantrópica (1500-1874), cuja centralização eram as Santas Casas de Misericórdia e a roda dos expostos; filantrópico-higienista (1874-1922), na qual os médicos, em uma visão da sociedade científica, sobressaiam-se no tratamento referente às crianças frente aos juristas, buscando organizar os espaços públicos e coletivos; a assistencial (1924-1964), surgindo o Código de Menores e todo o aparato judicial montado para auxiliar o Estado na responsabilidade legal pela tutela das crianças órfăs e abandonadas e, com isso, dirigindo esforços para oportunidades de trabalho; institucional pós-64 (1964-1990), em que tem início a Funabem e a FEBEM, em conformidade com a Doutrina da Segurança Nacional, editando-se o Código de Menores promulgado em 1979 que objetivava a inserção dos 'menores' no serviço militar; e, por fim, a desinstitucionalização (1990 aos dias atuais), que advém da Constituição Federal de 1988 e a consequente chegada do Estatuto da Criança e do Adolescente, em 1990, sendo a responsabilidade pela criança e pelo adolescente compartilhada entre a família, a sociedade e o Estado.

Percebe-se que a proposta vigente, que também se constitui como um desafio para o século XXI, é a desinstitucionalização de crianças e adolescentes, na medida em que ano após ano, mesmo após a vigência do ECA, é possível verificar os efeitos negativos que tal prática exerce no desenvolvimento humano desses cidadáos, como atrasos no desenvolvimento emocional, físico e cognitivo. Ao militarem pela eliminação da institucionalização, Costa e Pop (2017), em documento redigido para a Associação Brasileira Terra dos Homens, apresentam diversas questóes interligadas às práticas institucionais que são extremamente prejudiciais às crianças e ado- 
lescentes, como a rotina em forma de cronograma e com pouca flexibilidade, a despersonalização - dado que há pouco espaço para desenvolverem e demonstrarem sua personalidade -, a falta de tempo, capacitação e supervisão dos educadores e o efeito devastador na autonomia dos acolhidos, pois deixam de desenvolver um conjunto básico de habilidades práticas e competências para uma vida independente.

A Lei $n^{\circ} 8.069 / 90$ trouxe o termo 'abrigo' como um dos regimes de programas de proteçáo e socioeducativos destinados a crianças e adolescentes, sendo substituído por 'acolhimento institucional' com o advento da Lei no 12.010/09. O acolhimento institucional pode ocorrer em modalidades mais abrangentes, sendo elas: a) os abrigos institucionais; b) as casas-lares; c) as famílias acolhedoras e d) as repúblicas, esta uma definição oriunda do Plano Nacional de Promoção, Proteção e Defesa do Direito de Crianças e Adolescentes à Convivência Familiar e Comunitária (Brasil, 2006) e das Orientaçôes Técnicas: Serviços de Acolhimento para Crianças e Adolescentes (BRASIL, 2009). O supracitado Plano propóe um reordenamento dos serviços existentes em âmbito nacional, para que, em conjunto com o Sistema de Garantia de Direitos das Crianças e Adolescentes, fosse possível repensar alguns paradigmas e estruturas institucionais, refletir sobre as políticas pedagógicas e promover as articulaçóes necessárias (GULASSA, 2010, p. 14), principalmente com a rede socioassistencial do município (saúde, educação, assistência social, esporte, cultura e outros).

As normativas em questão surgiram para que se possa ter um parâmetro de como reorganizar os serviços, atentando-se à Constituição Federal de 1988 e ao ECA. Isso porque as marcas históricas deixadas pela institucionalização em nosso país remetem a situaçôes gravíssimas, que reproduzem uma cultura de violência, opressão, humilhação e exclusão social, dando ênfase ao estigma do 'menor'. Com isso, ainda se luta para superar o mantido "abismo infranqueável entre infâncias privilegiadas e menores marginalizados.” (RIZZINI; PILOTTI, 2011, p. 16) Pretendendo uma sociedade democrática e participativa, o ECA trouxe um renovado paradigma de cunho jurídico, político e administrativo, apostando no atendimento à criança e ao adolescente como componente das políticas sociais. Ocorre que, pensando na questão legislativa, Silva (1997, p. 71) alerta: 
O Brasil sempre se deparou com esta contradição: por um lado, adota posturas avançadas na legislação, acompanhando os principais avanços consagrados nos tratados e nas convençóes internacionais, mas, por outro, essa mesma legislação avançada serve para mascarar e camuflar uma prática arcaica e discriminatória.

É nítida a preocupação do legislador com a questão da infância e da juventude no Brasil quando traz elementos que buscam um distanciamento em relação às práticas repressivas, tratando a infância e a adolescência com absoluta prioridade e em uma perspectiva de direitos humanos, em um evidente esforço de humanização do passado. Nesse sentido, Gonçalves (2005, p. 41) relembra que as prioridades se invertem:

No modelo assistencial-repressivo, predominava o entendimento de que a criança tinha obrigaçôes e deveres legais, e a autoridade, o direito de punir o comportamento da mesma; no modelo da proteção integral, predomina a percepção da criança como sujeito privilegiado de direitos, que a autoridade tem o dever de fazer cumprir. No primeiro caso, a autoridade detém prioritariamente o direito de punir; no segundo, tem principalmente o dever de atender.

A relação da criança e do adolescente com o Estado e com a sociedade passaria, então, a ser redesenhada. Mas a existência de uma lei específica para essa população não significaria uma mudança efetiva no acesso aos direitos e na cultura existente nos locais de atendimento, pois "uma lei promulgada será ineficaz se não estiver legitimada socialmente." (PASSETTI, 2008, p. 371) Infelizmente, no senso comum prevaleceria o discurso de que o ECA, ao atender a perspectiva dos direitos humanos, facilitaria a 'proliferação criminosa' de adolescentes, dado o seu viés de impunidade implantado por discursos eleitoreiros e midiáticos, tendo sido inclusive atacado em recente campanha presidencial de 2018, em que um dos candidatos menciona que o ECA deveria ser "rasgado e jogado na latrina." (SOARES, 2018). Certamente é um indicativo do quanto ainda 
necessitaria ser realizado para que o reconhecimento de direitos se torne na prática uma realidade.

Segundo o texto do Plano Nacional de Promoção, Proteção e Defesa do Direito de Crianças e Adolescentes à Convivência Familiar e Comunitária (Brasil, 2006), verificou-se, por meio de um levantamento nacional, que a institucionalização ainda tem sido utilizada de maneira indiscriminada, em desatendimento ao caráter de excepcionalidade previsto no ECA, que determina no $₫ 1^{\circ}$ do artigo 101 que "o acolhimento institucional e o acolhimento familiar são medidas provisórias e excepcionais, utilizáveis como forma de transição para reintegraçáo familiar ou, não sendo esta possível, para colocação em família substituta, não implicando privação de liberdade." (BRASIL, 1990, grifos nossos) Ademais, os dados apurados evidenciariam características típicas de exclusão social, indicando que os abrigos no Brasil são 'depósitos' de pobreza e desvalorização social. A partir disso é possível evidenciar que, apesar da intenção legal pela desinstitucionalização, ainda convivemos com práticas equivocadas de 'proteção' por parte dos operadores das políticas públicas que, antes de procurar a superação da violação do direito provocada pelo afastamento da família, optam pelo encaminhamento às instituiçóes. (RIZZINI, 2006, p. 9)

Segundo as "Orientaçôes Técnicas: Serviços de Acolhimento para Crianças e Adolescentes" (BRASIL, 2009), o abrigo institucional deveria ter aparência semelhante de uma residência, oferecendo ambiente acolhedor e condiçóes institucionais para o atendimento com padrôes de dignidade. $\mathrm{O}$ atendimento deveria ser em pequenos grupos e personalizado, colaborando com o convívio familiar e comunitário das crianças e adolescentes atendidos, bem como a utilização dos equipamentos e serviços disponíveis na comunidade local. As especializaçóes e atendimentos exclusivos deveriam ser evitados e deveria ser garantida a convivência entre grupos de parentesco, sendo que o número máximo de usuários por equipamento deveria ser de 20 (vinte) crianças e adolescentes, sendo essas de 0 (zero) a 18 (dezoito) anos.

Quanto ao educador/cuidador que atua no abrigo, define-se que sua formação mínima seja a de nível médio e capacitação específica, com desejável experiência em atendimento a crianças e adolescentes, sendo que as principais atividades desenvolvidas seriam: a) cuidados básicos 
com alimentação, higiene e proteção; b) organização do ambiente (espaço físico e atividades adequadas ao grau de desenvolvimento de cada criança ou adolescente); c) auxílio à criança e ao adolescente para lidar com sua história de vida, fortalecimento da autoestima e construção da identidade; d) organização de fotografias e registros individuais sobre o desenvolvimento de cada criança e/ou adolescente, de modo a preservar sua história de vida; e) acompanhamento nos serviços de saúde, escola e outros requeridos no cotidiano (quando se mostrar necessário e pertinente, um profissional de nível superior deveria também participar deste acompanhamento); f) apoio na preparação da criança ou adolescente para o desligamento, orientado e supervisionado por um profissional de nível superior. (BRASIL, 2009)

Com tais descriçóes, os abrigos institucionais passariam a buscar profissionais denominados educadores sociais para atuarem nesses espaços. Toma-se como exemplo, para contextualização do presente artigo, a experiência da autora como educadora social no município de Caxias do Sul/RS. De acordo com o Plano Municipal dos Serviços de Acolhimento Institucional para Crianças e Adolescentes do município, referente ao período de 2014 a 2017, o município, que possui em torno de 465 mil habitantes segundo dados do IBGE, oferta três serviços na modalidade abrigo institucional, com 20 (vinte) vagas cada: Casa de Acolhimento Institucional Sol Nascente, Abrigo Estrela Guia e Casa Abrigo Recanto Amigo. Os dois primeiros são públicos, administrados pela Fundação de Assistência Social de Caxias do Sul/RS (FAS) e o último é um serviço conveniado, consistindo em parceria público-privada.

Tomando como parâmetro os abrigos que são públicos, a contratação dos educadores sociais ocorre por meio de concurso público para o cargo de educador social, com exigência de ensino médio completo e aprovação em curso introdutório de formação para educadores sociais, cujo conteúdo programático integrava, dentre outras questôes, os fundamentos da educação social e das atividades socioeducativas e a pedagogia da autonomia. Segundo o Portal de Transparência do município, em dezembro de 2018 a FAS, órgão gestor da Política Pública de Assistência Social, contava com 98 (noventa e oito) educadores sociais distribuídos entre os serviços de proteção social básica e especial, de média e alta complexidade. Em torno 
de 44 (quarenta e quatro) educadores sociais estão lotados nos dois abrigos supracitados, Estrela Guia e Sol Nascente.

A FAS foi instituída no município pela Lei n. ${ }^{\circ} 4.419$, de 4 de janeiro de 1996, e, consequentemente, todos os educadores sociais foram nomeados após esse período em que já estava em vigor tanto a Constituiçáo Federal de 1988 quanto o Estatuto da Criança e do Adolescente de 1990. No entanto, os serviços seriam reordenados aos poucos, com o advento do Plano Nacional de Promoção, Proteção e Defesa do Direito de Crianças e Adolescentes à Convivência Familiar e Comunitária (BRASIL, 2006) e das Orientações Técnicas: Serviços de Acolhimento para Crianças e Adolescentes. (BRASIL, 2009)

A partir dessa breve contextualização, denota-se também a importância de pensar no papel do educador social no cotidiano de um abrigo. Sabe-se que em tempos de FEBEM, por exemplo, a lógica de trabalho dos denominados 'agentes' era baseada na repressão e no autoritarismo. Hoje, em consonância com Souza Neto (2010, p. 42), seria possível afirmar que adaptando-se a doutrina da proteção integral nas políticas públicas a educação social ganharia credibilidade. Então, considerando que apesar das tentativas de desinstitucionalização ainda não seria possível propor a extinção desses ambientes em curto prazo, como pensar o acolhimento com o envolvimento da educação social? Quem seria o educador social de abrigo? Seria possível trabalhar, metodologicamente, a questão da pedagogia social nesse espaço? O que poderiam esses educadores sociais, servidores ou contratados, militantes ou voluntários, fazer pelas crianças e adolescentes?

\section{Epistemologia da Pedagogia Social: a Esperança no Território Institucional}

De acordo com Passetti (2008, p. 372), “entre a intenção do ECA e a realidade política, preponderou a internação, o que expressa o fracasso da intenção educativa", isso porque, em que pese o investimento de cunho legislativo para a desinstitucionalização, na prática ainda encontramos abrigos lotados, principalmente pela falta de condiçóes dignas de vida de muitas famílias brasileiras. A pobreza, a fome e a negligência ainda levam 
crianças e adolescentes aos abrigos, pois apesar de alguns avanços executados nas últimas décadas para lidar com a desigualdade social no país, permaneceram os resquícios da intervenção assistencialista e autoritária no âmbito da família. (RIZZINI; RIZZINI, 2004, p. 14)

No entanto, enquanto empregam-se esforços pela manutenção dos vínculos familiares e comunitários desses pequenos cidadãos, precisa-se olhar também para o nítido fracasso da intenção educativa, mormente porque além da positiva alteraçáo legislativa, necessita-se de um empenho por parte dos operadores das políticas sociais. Não sendo possível pensar em uma perspectiva de extinção desses locais - por muitos estudiosos denominados 'instituiçóes totais ${ }^{1}$-, pelo menos em curto prazo, seria necessário criar estratégias de ação e resistência dentro do espaço institucional na busca constante de alternativas, de ações afirmativas.

Para Souza Neto (2010, p. 30), o educador social possui uma capacidade criativa e um modo de intervenção que "constituem um tecido social que ajuda os sujeitos envolvidos a compreender e a extrair forças emancipadoras de uma realidade multiforme, contraditória e desafiadora." Conforme Gadotti (2012), a educação social vem sendo reconhecida como práxis da pedagogia social e dialoga com a educação popular e com a educação comunitária, integrando-se ao campo da pedagogia crítica. O autor também refere que, ao se unirem a uma mesma corrente, compartilham de uma mesma perspectiva utópica da educação "porque esse educador educa em funçáo de um sonho na busca de um mundo justo, produtivo e sustentável para todos e todas. Para intervir e mudar o mundo que deseja transformar, ele precisa conhecer a realidade onde atua, com os pés no chão, mas procurando enxergar longe.” (GADOTTI, 2012, p. 11) Espera-se ainda que o educador social tenha domínio técnico-pedagógico específico e com isso exerça a sua função de empoderar o indivíduo. Em consonância, Caliman (2010, p. 358) explica que o processo de empoderamento ocorre quando as pessoas passam a ser motivadas de dentro para fora, promovendo a capacidade de administrarem os seus riscos.

Romans e Petrus (2003), ao fazerem uma aproximação com a sociologia, conduzem a educação social para a missáo de educar para a participaçáo social, trabalhando as próprias condutas dos cidadãos em suas relaçôes com a família, comunidade, trabalho etc., sob pena de se manter em um paradigma tradicional de educação: 
A educação social está obrigada a iniciar toda ação intercultural a partir do pressuposto: o respeito pela cultura de origem do cidadáo. Se queremos frear a atual incidência da desigualdade e da polarização social, pensamos que somente cabe uma estratégia: as políticas públicas. E dentro delas, acreditamos, a educação social terá a cada dia um papel mais importante, principalmente se for capaz de detectar corretamente as necessidades de todos aqueles que se veem obrigados a construir uma nova “identidade". (ROMANS; PETRUS, 2003, p. 59, grifo nosso)

Ressalta-se que a conceituação da educação social possui entendimentos diversos, inclusive no que tange a sua relação com a educação popular defendida por Freire. Santos (2019, p. 51) infere que "o uso da educação social no Brasil nasce da política da assistência social e na área da educação toma-se essa expressão como uma nova área a ser implantada, difundida e reconhecida na universidade." A pedagogia social, por seu turno, é relacionada como aporte político-pedagógico e epistemológico da educação popular (NETO; OLIVEIRA, 2018) e como uma ciência que é sensível à dimensão da sociabilidade humana que oferece as bases metodológicas e teóricas para a educação social (CALIMAN, 2010). O campo de conceituação teórica, portanto, é amplo e segue em construção, sendo imprescindível para que o educador social possa amparar o seu quefazer, devendo ser valorizada também a colaboração empírica.

No abrigo, valorizar a cultura de origem do acolhido é tarefa destinada ao educador, porém não é tarefa simples. Primeiramente, é de suma importância que o educador possa ter acesso aos prontuários (formalmente denominados como PIA - Plano Individual de Atendimento) ${ }^{2}$, "considerando a delicadeza das memórias e sentimentos ali implicados." (ELAGE, 2010, p. 79) Desde o momento de chegada no serviço de acolhimento é importante ir construindo uma relação de confiança com a criança ou adolescente, mostrando a possibilidade de novos vínculos significativos, e essa relação de confiança se constrói por meio de uma presença atenta. Mesmo que se trabalhe na perspectiva de provisoriedade do educando, o tempo permanecido nesse ambiente será para ele uma experiência significativa, ainda que enfrentando um cotidiano que é marcado pelo ritmo do coletivo. Em consonância, "o processo de aprendizagem deve propiciar aos 
educandos instrumentos para saberem lutar e construir o sentido da vida." (SOUZA NETO, 2010, p. 36)

Nessa acepção de acolhimento, Antunes e Garroux (2008) trazem como modelo de educaçáo social o que chamam de pedagogia do cuidado. Referenciando a importância dos embasamentos teóricos, dos planejamentos e procedimentos, os autores valorizam primordialmente a capacidade de trabalhar com as emergências, com os gritos desses educandos, com a administraçáo de conflitos, sempre amparado por uma ideologia e um método, destacando-se que "as palavras de uma verdadeira educadora possuem poder essencial de transformação quando chegam no momento necessário, ditas pela sinceridade de quem não transmite informação, mas busca estimular pensamentos." (ANTUNES; GARROUX, 2008, p. 91)

Ademais, ao abordar a educação não formal com uma perspectiva de fortalecimento do exercício da cidadania, Gohn (2010, p. 16) realça que apesar de existir a figura do educador social, o principal educador é o 'outro', ou seja, aquele com o qual ele interage e se integra, produzindo novos conhecimentos. Tavares e Souza Neto (2017) destacam que é a partir do contexto situacional do sujeito que deveria ser pensada a educaçáo, notando-se como ele age e reage à procura da liberdade, e como aprende a ser, a conviver e a fazer.

As adversidades existentes no desenvolvimento da criança e do adolescente no ambiente institucional é um obstáculo a ser enfrentado pelo educador social, pela dificuldade de formar indivíduos autônomos e que consigam estabelecer uma relação imune às instituições de tutela (SILVA, 1997, p. 9). De acordo com Violante (1984, p. 166-167), em pesquisa realizada antes de vigorar o ECA, os "menores" retrataram que "o internamento é representado como impossibilidade para sua experiência de vida, tornando-os ignorantes não só por afastá-los do mundo externo, como por confina-los a um mundo monótono - sempre com as mesmas pessoas, as mesmas cores, as mesmas rotinas." Quase quarenta anos depois, essa situação ainda é uma constante dentro do abrigo, como foi registrada no diário de campo da pesquisa, em que uma adolescente refere à pesquisadora: "para ti é fácil, né tia... sai daqui, vive uma vida normal e retorna... eu só queria ser livre." A impressão é que, ao viver no espaço-abrigo, a abertura para o mundo 'real' é quase inexistente, criando sensaçôes de desproteção 
e abandono, aprisionando-os dentro da dinâmica institucional. (ALTOÉ, 2008, p. 291)

Não obstante, ao abordar-se o tema na perspectiva da educação social, vinculando o olhar para os oprimidos, é imprescindível adentrar nos pensamentos freireanos e sua influência na construção da educação social no país. Ao abordar o papel do trabalhador social no processo de mudança, Freire (1981) pontua a questão do olhar do trabalhador social, da admiraçáo perante o outro e o quanto isso difere da pura ingenuidade baseada no já instituído assistencialismo. Disserta sobre a complexidade da estrutura social em que esse trabalhador atua e o seu posicionamento entre a permanência no status quo ou a participação na mudança, destacando-se que, optando pela segunda, ciente de que não há neutralidade, deve-se cuidar para náo permear na manipulação e impor sua opçáo aos demais, que classifica como instrumento de desumanizaçáo, bem como não se sentir 'o' agente da mudança e sim 'um' de seus agentes. Ressalta que o 'papel' do trabalhador social que optou pela mudança não é tentar a conscientização dos sujeitos com quem trabalha, mas se conscientizar com eles.

Destaca-se, outrossim, a importância de se trabalhar a partir de sujeitos de transformação, considerando que "o trabalhador social que opta pela mudança não teme a liberdade, não prescreve, não manipula, não foge da comunicação, pelo contrário, a procura e vive." (FREIRE, 1981, p. 51) Assim, mesmo que as pessoas tenham sido colocadas na condiçáo de objetos de uma dada estrutura na sociedade, como é o caso do abrigo, o papel do trabalhador social está justamente ligado à mudança dessa situação, para que se promova a condição de sujeito do cidadáo, de participante ativo. Ademais, o trabalhador social deve estar sempre atento sobre a importância da reflexão-ação e de que nessa construção se permita a colaboração dos sujeitos assistidos, pois é a maneira de se transformar os fatalismos em esperanças, como destaca:

Esta mudança de percepção que se dá na problematização de uma realidade concreta, no entrechoque de suas contradiçóes, implica um novo enfrentamento do homem com sua realidade. Implica admirá-la em sua totalidade: vê-la de "dentro" e, desse "interior", separá-la em suas partes e voltar a admirá-la, ganhando assim uma visão mais crítica e profunda da sua si- 
tuação na realidade que não condiciona. Implica uma "apropriação" do contexto; uma inserção nele; um não ficar "aderido" a ele; um não estar quase "sob" o tempo, mas no tempo. Implica reconhecer-se homem ${ }^{3}$. Homem que deve atuar, pensar, crescer, transformar e náo adaptar-se fatalisticamente a uma realidade desumanizante. (FREIRE, 1981, p. 60 , grifo nosso)

Entende-se primordial a contextualização da presente pesquisa a partir da citação acima, na medida em que no ambiente institucionalizado realmente há uma aproximação com o que Freire entende por um mundo criado do qual náo se pode fugir, e o seu funcionamento se dá tanto pelos educadores e demais profissionais quanto pelos acolhidos, tornando-se substancial a análise do espaço e da motivação de cada um nesse processo que deve ser, sobretudo, educativo. Sobrelevam-se também os apontamentos realizados por Freire em 1959, em sua tese de concurso para a cadeira de História e Filosofia da Educação na Escola de Belas-Artes de Pernambuco, intitulada Educação e atualidade brasileira, pois traz relatos que classifica como "experiência de educação social" e pondera com criticidade sobre o assistencialismo das instituiçôes e a ausência de participação na tomada de decisão que impacta os cidadãos que são atendidos nesses locais:

Cada vez mais compreendemos menos a hipertrofia dessas instituiçóes assistenciais, perigosamente alongadas em assistencialistas, levando-as a resolver os problemas de seus clientes, de seus "assistidos", digamos melhor, quando resolvem, sem sua colaboração. Sem consultá-los. A escolher até suas distrações. A organizar suas festas. A criar seus clubes e associaçóes. A interferir constantemente na sua vida. A alterar os estatutos de seus clubes, tudo isto de cima para baixo. Antidemocraticamente. (FREIRE, 2001, p. 19)

Com a vivência diária em uma instituição de acolhimento, a pesquisa revela que quase sessenta anos depois das palavras de Freire o formato assistencialista ainda se repete em alguns momentos. Diante da estrutura existente nas instituições e das demandas apresentadas pelo contexto social 
e econômico existente, a promoção da autonomia dos acolhidos, notadamente os adolescentes, sujeitos da presente pesquisa, ficaria em segundo plano, o que acarretaria danos irreversíveis em cidadãs e cidadãos que com tão pouco tempo de vida já carregam muitas marcas, fruto da injusta estrutura social na qual vivemos. Nesse sentido, Souza Neto (2010, p. 34) reforça que é levando em conta o protagonismo do indivíduo que será possível planejar uma prática emancipadora, já que, "tanto quanto o sentido da vida, o protagonismo é, frequentemente, relegado a um segundo plano."

Paulo Freire (2001, p. 19) costumava defender em suas obras a importância de que os jovens participem plenamente das tomadas de decisão, de que não se espere que as experiências democráticas só sejam atribuídas e 'cobradas' deles quando atingirem a maioridade. Nesse sentido, infere que mesmo diante dos riscos de que as decisóes tomadas possam ser equivocadas, é o caminho indicado, pois, afinal, é decidindo que se aprende a decidir (FREIRE, 2009, p. 106). Em consonância, defende a liberdade, mesmo assumindo que dela derivam riscos, mas sobretudo porque é imperativo para que se viva a eticidade. Trabalhando a partir da liberdade se constrói a possibilidade de desenvolvimento de autonomia, entendendo-se que "é com ela, a autonomia, penosamente construindo-se, que a liberdade vai preenchendo o "espaço" antes "habitado" por sua dependência. Sua autonomia que se funda na responsabilidade que vai sendo assumida." (FREIRE, 2009, p. 94, grifos do autor)

Observa-se que em Pedagogia da Autonomia Freire (2009) parece abordar o assunto partindo de um contexto de convivência familiar 'padrão', qual seja, pais e filhos, talvez pensando na suposta 'família tradicional brasileira'. Institucionalmente, o processo é ainda mais burocrático e complicado, pois o trabalho desenvolvido com os adolescentes dependeria dos regramentos da instituição, do projeto político pedagógico - quando existente -, da politicidade e conscientização dos educadores, da confiança entre educador e educando, entre tantas outras questôes que são abordadas na presente pesquisa, a partir do seguinte pensamento:

O que é preciso, fundamentalmente mesmo, é que o filho assuma eticamente, responsavelmente, sua decisão, fundante de sua autonomia. Ninguém é autônomo primeiro para depois decidir. A autonomia vai se constituindo na experiência 
de várias, inúmeras decisóes, que váo sendo tomadas. Por que, por exemplo, não desafiar o filho, ainda criança, no sentido de participar da escolha da melhor hora para fazer seus deveres escolares? Por que o melhor tempo para esta tarefa é sempre o dos pais? Por que perder a oportunidade de ir sublinhando aos filhos o dever e o direito que eles têm, como gente, de ir forjando sua própria autonomia? Ninguém é sujeito da autonomia de ninguém. Por outro lado, ninguém amadurece de repente, aos 25 anos. A gente vai amadurecendo todo dia, ou náo. A autonomia, enquanto amadurecimento do ser para si, é processo, é vir a ser. Náo ocorre em data marcada. É neste sentido que uma pedagogia da autonomia tem de estar centrada em experiências estimuladoras da decisáo e da responsabilidade, vale dizer, em experiências respeitosas da liberdade. (FREIRE, 2009, p. 107, grifos nossos)

Parte-se do pressuposto inegável que o desenvolvimento da autonomia em adolescentes que estão institucionalizados é demasiadamente distinto dos 'outros', frente a todas as situaçôes que já vivenciaram e também àquelas a que estão expostos com a institucionalização, além das suas projeçóes sobre a sua saída do abrigamento. A escolha de uma concepção freireana legitima-se por ser uma das relevâncias centrais de sua obra e tarefa fundamental no ato de educar, vinculada ao paradoxo $\mathrm{da}$ autonomia/dependência. Assim, torna-se compreensível a ideia de que o adolescente acolhido, ciente de sua dependência frente à instituição, possa refletir criticamente sobre ela e sobre o processo de decisão e humanização que o tornará autônomo. Como infere Machado (2018, p. 61), "a autonomia também se caracteriza pela confiança que o sujeito possui no seu histórico particular, é o desenvolvimento do sujeito histórico, de democracia e liberdade que a autonomia vai se construindo." $\mathrm{O}$ educador social, portanto, deve permitir que tal condição ocorra a partir da contextualização de vida do acolhido, do diálogo aberto estabelecido com ele sobre as diversas possibilidades que surgem, mesmo encarando uma vivência de abandono e violência, buscando náo alienar esses cidadãos e cidadâs do que os compóe individualmente. 
A partir dessa perspectiva, aparentemente negativa, levanta-se a possibilidade de identificar um viés de trabalho esperançoso, baseado na epistemologia da pedagogia social, unindo os desafios e incertezas encontrados na pesquisa, pautando-se na premissa de trabalhar a realidade social do educando como uma educaçâo que possibilite a discussão corajosa de sua problemática, inserindo-se nela, analisando criticamente os seus achados (FREIRE, 2001, p. 38). Sabe-se que trabalhos envolvendo jovens necessitam de adaptaçóes para que se possa vincular com sua cultura, conhecendo seu território, sua linguagem, suas expressóes culturais, entre tantos outros aspectos. No entanto, quando a abordagem é relacionada a jovens em situação de vulnerabilidade e, além de tudo, institucionalizados, que carregam consigo uma série de estigmas, necessita-se adotar uma epistemologia conexa com uma prática científica que, sob inspiraçáo freiriana, questiona: "A favor de quem estudo? Em favor de quem? Contra que estudo? Contra quem estudo?" (FREIRE, 2009, p. 77) As percepçôes do papel do educador social são diversas justamente pela trajetória que insere o sujeito nesta posição.

Náo existem verdades universais, manuais ou regras simples que possam determinar como se dará o trabalho do educador social dentro do abrigo, existem experiências acumuladas. Também não há como falar em processo de coisificaçáo, pois, como ressalta Souza Neto (2010, p. 54), são relaçóes dinâmicas que envolvem o cotidiano, as emoçóes, a realidade social dos envolvidos. Com isso, existem perspectivas de trabalho que tomam por base a visão de mundo e o modo de ser dos oprimidos, valorizando seus atos criativos e transgressores, construindo perspectivas e utopias. Os "conhecimentos de experiência feitos" são cruciais para o trabalho porque por meio deles é possível a promoção da curiosidade espontânea para curiosidade epistemológica (FREIRE, 2009, p. 88), resultando na produção do conhecimento sobre a realidade vivida e a capacidade de transformá-la em face da assunção da consciência crítica.

Obviamente, é imprescindível relembrar que a maioria das instituições ainda possuem vestígios autoritários e práticas engessadas, exigindo uma organização resistente dos educadores sociais em busca de mudanças de regramentos, a criação ou revisão do projeto político-pedagógico, o envolvimento com a rede socioassistencial e com a comunidade. Assim sugere Santos et al (2017, p. 119 - grifo no original): 
É sabido que os atravessamentos, limites institucionais estão dados; cabe-nos olhar para eles e pensar estratégias de superar e erradicar as situaçóes que contribuem para a violação de direitos. Práticas de náo cuidado muitas vezes se apresentam no cotidiano profissional, e assim se coloca o desafio de analisar os discursos na prática, suas reproduçôes e repetições, não há de se reduzir se há certo e errado, ou verdadeiro e falso, mas é minimamente necessário "conversar sobre", analisar, interpretar e, se necessário transformar.

A própria luta em busca de uma mudança na história dessas crianças e adolescentes já é símbolo de esperança. Mudança essa que não deve visar a negação de uma história em razão de seus percalços, mas a sua compreensão e transformação. $\mathrm{Na}$ imobilidade não há esperança, pois, como garante Freire (2012, p. 80), para ser tem que estar sendo. O quefazer permanente do educador é a própria esperança.

\section{Consideraçóes finais}

Tendo como referência a trajetória cronológica da institucionalização de crianças e adolescentes no país e a consolidação das atuais normativas legais na busca pela convivência familiar e comunitária como forma de resolução das questóes que envolvem a infância e a juventude, pretendeu-se evidenciar que a prática está distante da expectativa legal.

Mesmo que possa se afirmar a existência de um distanciamento significativo em relaçáo aos antigos orfanatos e internatos do que são os abrigos hoje, ainda é nítido, segundo as pesquisas e documentos governamentais sobre o tema, que existe um número exacerbado de crianças e adolescentes crescendo nesses ambientes, colocando em risco o seu adequado desenvolvimento emocional, físico e cognitivo.

No entanto, não é possível fechar os olhos para a realidade: enquanto existirem abrigos e existirem aplicaçóes de medidas protetivas de institucionalização nessa modalidade, é necessário encará-la, trabalhar com ela, ressignificar os espaços, as atuações profissionais, as vivências das crianças e dos adolescentes. Se de um lado buscamos outras modalidades 
de enfrentamento dessa situação social, por outro não podemos fechar os olhos para as instituiçóes ainda existentes, sendo imprescindível lutar pela qualidade do serviço e pela garantia aos direitos humanos dos acolhidos, tanto investindo em pesquisa acadêmica quanto em militância em prol desses direitos. E nessa educação utópica, entre a denúncia e o anúncio, buscamos um futuro que não repita o presente, buscamos um engajamento arriscado (FREIRE, 1981), principalmente em épocas em que os discursos contrários aos direitos humanos proliferam.

Avalia-se que uma possibilidade de mudança estaria no papel do trabalhador social que atua nesse espaço, na pedagogia social que une as ciências sociais, os serviços sociais e a educação, visando colaborar com o bemestar e a recuperação dos indivíduos que precisam de apoio (CALIMAN, 2010, p. 366). Acredita-se que o educador social que se filie a uma epistemologia conexa com uma prática científica libertária e em conformidade com as práticas educativas freireanas possa ser o fio condutor de esperança dos espaços institucionais.

A convivência com o espaço institucional, sistematizando a própria prática, permitiria vislumbrar a produçáo de um conhecimento a partir dela. Identifica-se como um desafio da educação social estar inserido no ambiente institucional, não com perspectivas de julgamento, como já estão acostumados as crianças e os adolescentes estigmatizados, mas com um olhar atento para questionar e para desnaturalizar as coisas. É no dia a dia que o educador social se forma, descobre seu caminho e sua forma de ser educador. A pedagogia social contribui como formação científica e a educação social como vivência cotidiana, entre a racionalidade e a irracionalidade. É da convivência com o outro que surge a reflexão, enquanto a esperança brota do cotidiano, como caminhada, como compromisso ético. Esperança que vive no corpo de cada um: educador e educando. Como afirma Freire (2016, p. 15), precisamos de esperança crítica assim como o peixe precisa da água despoluída.

Ser educador social no abrigo é educar para além da razão crítica, mas com o corpo inteiro: sentimentos, emoçóes, dúvidas, desejos, medos, paixôes, frustaçóes (FREIRE, 2009, p. 12). É preciso encarar uma realidade distante da legislação, realidade que é desacreditada pela sociedade e movida muitas vezes por interesses políticos. É sobreviver à desesperança. É acreditar na utopia, no inédito viável, no sonho possível. 


\section{Notas}

1 Referente às instituiçôes totais, recomenda-se, em especial, a leitura de: GOFFMAN, Erving. Manicômios, prisóes e conventos. São Paulo: Perspectiva, 2008; FOUCAULT, Michel. Vigiar e punir: nascimento da prisão. Rio de Janeiro: Vozes, 2000.

2 O PIA é um documento obrigatório, de acordo com o ECA, sendo "um instrumento que norteia as açôes a serem realizadas para viabilizar a proteção integral, a reinserção familiar e comunitária e a autonomia de crianças e adolescentes afastados dos cuidados parentais e sob proteçáo de serviços de acolhimento. É uma estratégia de planejamento que, a partir do estudo aprofundado de cada caso, compreende a singularidade dos sujeitos e organiza as açôes e atividades a serem desenvolvidas com a criança/adolescente e sua família durante o período de acolhimento." (BRASIL, 2018, p. 7) A sua elaboração fica a cargo da equipe técnica do serviço de acolhimento.

3 Ao utilizar-se a expressão 'homens', é necessária a abertura para uma análise da crítica existente sobre a escrita de Paulo Freire, na medida em que existe o entendimento de que o autor utiliza uma linguagem sexista, o que é visto como um exemplo negativo pelas feministas contemporâneas. Ê uma questão de gênero que merece atenção, buscando-se para tanto apoio na interpretaçấo da teórica Bell Hooks, que entende não existir contradição entre ser feminista e ao mesmo tempo valorizar a obra de Paulo Freire, considerando que é o próprio pensamento feminista que torna possível que a visão de mundo do autor não seja apreciada de forma passiva e sim com uma crítica feminista. Segundo a autora, "o sexismo de Freire é indicado pela linguagem de suas primeiras obras, apesar de tantas coisas continuarem libertadoras. Não é preciso pedir desculpas pelo sexismo. O próprio modelo de pedagogia crítica de Freire acolhe o questionamento crítico dessa falha na obra. Mas questionamento crítico não é o mesmo que rejeição." (HOOKS, 2017, p. 70)

\section{Referências}

ALTOÉ, Sonia. Infância perdida: o cotidiano nos internatos-prisão. Rio de Janeiro: Centro Edelstein de Pesquisas Sociais, 2008.

ANTUNES, Celso; GARROUX, Dagmar. Pedagogia do cuidado: um modelo de educação social. Rio de Janeiro: Vozes, 2008.

ASSIS, Simone Gonçalves de; FARIAS, Luis Otávio Pires (Org.). Levantamento nacional das crianças e adolescentes em serviço de acolhimento. São Paulo: Hucitec, 2013.

BRASIL. Lei no 8.069/90. Dispóe sobre o Estatuto da Criança e do Adolescente e dá outras providências. 1990 .

BRASIL. Orientações técnicas: serviços de acolhimento para crianças e adolescentes. Brasília: 2009.

BRASIL. Orientaçôes técnicas para elaboração do Plano Individual de Atendimento (PIA) de Crianças e Adolescentes em Serviços de Acolhimento. Brasília: Ministério do Desenvolvimento Social, 2018.

BRASIL. Plano Nacional de Promoção, Proteção e Defesa do Direito de Crianças e Adolescentes à Convivência Familiar e Comunitária. Brasília: 2006. 
CALIMAN, Geraldo. Pedagogia social: seu potencial crítico e transformador. Revista de Ciências da Educação. UNISAL, São Paulo, ano XII, no 23, 2010, p. 341-368.

MOTA NETO, J. Colares da; OLIVEIRA, I. Apoluceno de. Contribuiçóes da educação popular à pedagogia social: por uma educação emancipatória na Amazônia. Revista de Educação Popular, v. 16, n. 3, jan. 2018, p. 21-35.

COSTA, Michela; POP, Delia. Um fim ao silêncio: fundamentos para eliminar a institucionalização de crianças e adolescentes. Rio de Janeiro: Terra dos Homens, 2017.

ELAGE, Bruna (Org.). História de vida: identidade e proteção. São Paulo: NECA Associação dos Pesquisadores de Núcleos de Estudos e Pesquisas sobre a Criança e o Adolescente, 2010.

FREIRE, Paulo. Ação cultural para a liberdade. Rio de Janeiro: Paz e Terra, 1981. Professora sim, tia não: cartas a quem ousa ensinar. São Paulo: Olho d’Água, 2009. . Educação e atualidade brasileira. São Paulo: Editora Cortez, 2001. . Educação e mudança. Rio de Janeiro: Paz e Terra, 1981. . Pedagogia da autonomia: saberes necessários à prática educativa. São Paulo: Paz e Terra, 2009. . Pedagogia da esperança. Rio de Janeiro: Paz e Terra, 2016. . Pedagogia do oprimido. Rio de Janeiro: Nova Fronteira: 2012.

GADOTTI, Moacir. Educação popular, educação social, educação comunitária: conceitos e práticas diversas, cimentadas por uma causa comum. Revista Diálogos: pesquisa em extensão universitária, IV Congresso Internacional de Pedagogia Social: domínio epistemológico, Brasília, v. 18, no 1, dez. 2012, p. 10-32.

GOHN, Maria da Glória. Educação não formal e o educador social: atuação no desenvolvimento de projetos sociais. Sáo Paulo: Cortez, 2010.

GONÇAVES, Hebe Signorini. Medidas socioeducativas: avanços e retrocessos no trato do adolescente autor de ato infracional. In: ZAMORA, Maria Helena (Org.). Para além das grades: elementos para a transformação do sistema socioeducativo. São Paulo: Loyola, 2005, p. 35-62.

GULASSA, Maria Lúcia Carr Ribeiro (Org.). Novos rumos do acolhimento institucional. São Paulo: NECA - Associação dos Pesquisadores de Núcleos de Estudos e Pesquisas sobre a Criança e o Adolescente, 2010.

HOOKS, Bell. Ensinando a transgredir: a educação como prática da liberdade. São Paulo: Martins Fontes, 2017.

MACHADO, Martha de Toledo. A proteção constitucional de crianças e adolescentes e os direitos humanos. São Paulo: Manole, 2003. 
MACHADO, Rita de Cássia de Fraga. Autonomia. In: STRECK, Danilo R.; REDIN, Euclides; ZITKOSKI, Jaime José. Dicionário Paulo Freire. Belo Horizonte: Autêntica Editora, 2018, p. 61.

PASSETTI, Edson. Crianças carentes e políticas públicas. In: DEL PRIORE, Mary. História das crianças no Brasil. São Paulo: Contexto; 2008, p. 347-375.

RIZZINI, Irene; PILOTTI, Francisco (Orgs.). A arte de governar crianças: a história das políticas sociais, da legislação e da assistência à infância no Brasil. São Paulo: Cortez, 2011.

RIZZINI, Irene (Org.). Acolhendo crianças e adolescentes. São Paulo: Cortez Editora, 2006.

RIZZINI, Irene; RIZZINI, Irma. A institucionalização de crianças no Brasil: percurso histórico e desafios do presente. São Paulo: Loyola, 2004.

ROMANS, Mercè; PETRUS, Antoni; TRILLA, Jaume. Profissão: educador social. Porto Alegre: Artmed, 2003.

SANTOS, Karine (Org) et al. Percursos com adolescentes: PPSC 20 anos de histórias. Porto Alegre: UFRGS/FACED, 2017.

SILVA, Roberto da. A formação da identidade criminosa em crianças órfãs e abandonadas. São Paulo: Editora Ática, 1997.

SOARES, Jussara. Bolsonaro diz que ECA deve ser 'rasgado e jogado na latrina'. Disponível em: <https:/oglobo.globo.com/brasil/bolsonaro-diz-que-eca-deve-serrasgado-jogado-na-latrina-23006248>. Acesso em: 21 jan. 2019.

SOUZA NETO, João Clemente de. Pedagogia social: a formação do educador social e o seu campo de atuação. In: Cadernos de Pesquisa em Educação PPGE-UFES, Vitória, v. 16, n. 32, jul./dez. 2010, p. 29-64.

SOUZA NETO, João Clemente de; TAVARES, Ezaques da Silva. Uma aproximação entre a pedagogia social e a comunidade. In: Revista de Pedagogia Social, Rio de Janeiro, v. 3, n. 1, mai. 2017. Disponível em: <http://www.revistadepedagogiasocial.uff.br/ index.php/ revista/article/view/13>. Acesso em: 20 jan. 2019.

VIOLANTE, Maria Lúcia Vieira. O dilema do decente malandro. São Paulo: Cortez, 1984.

Recebido em 5 fev. 20I9 / Aprovado em I6 dez. 2019

\section{Para referenciar este texto:}

HADDAD, S.; BAYS, I. Pedagogia social: epistemologia da esperança no território institucional. EccoS - Revista Científica, São Paulo, n. 51, eI I486, out./dez. 2019.

Disponível em: https://doi.org/I0.5585/EccoS.n5I.I I486. 